\title{
Postmenopausal Osteoporosis
}

Huiyong Shen ${ }^{1}$ Yue Sun ${ }^{2}$ Xun Liu²

${ }^{1}$ Department of Orthopaedics, the Second Affiliated Hospital of Sun Yat-Sen University ${ }^{2}$ Beijing Novartis Pharma Ltd., Beifing, China

\section{INTRODUCTION}

- Osteoporosis is a systemic skeletal disease, characterized by low bone mass and microarchitecture deterioration of bone tissue, with a consequent increase in bone fragility and susceptibility to fracture.

- Zoledronic Acid (Zol) has been demonstrated to be an effective therapy to treat postmenopausal osteoporosis (PMO) in Chinese women in a 12-months post-marketing observational study (ZOOM study). As an intravenous bisphosphonate, Zol is exclusively excreted via the kidneys.

\section{OBJECTIVE}

- The present report aimed to assess the renal function, safety data and tolerability for all the patients enrolled in the ZOOM study with once-yearly Zol $5 \mathrm{mg}$ treatment.

\section{METHODS}

- This was a 12-month, multicenter, non-interventional, post-marketing observational study.

- A total of 373 PMO patients from 30 different centers in China with baseline creatinine clearance $(\mathrm{CrCl})>35 \mathrm{ml} / \mathrm{min}$, bone mineral density (BMD) T score $\leq-2.5$ or T score $>-2.5$ with previous fragility fractures were recruited in the study. All the eligible patients received a single 15-minute infusion of Zol $5 \mathrm{mg}$ and followed up for 12 months. The BMD change at 12 month was the primary objective.

- Renal function [serum creatinine, $\mathrm{CrCl}$, and blood urea nitrogen(BUN)] was tested at baseline, 6 months and 12 months after the Zol infusion.

- Safety was assessed from adverse events and serious adverse events recorded by the investigators

- Tolerability satisfactions were evaluated by investigators and patients using the categories "very good","good","ordinary" and "bad"

\section{RESULTS}

\section{Renal Safety}

- Renal function assessment for all the patients showed that mean serum creatinine, $\mathrm{CrCl}$ and BUN maintained 12 months after treatment (creatinine $62.64 \pm 14.59 \mu \mathrm{mol} / \mathrm{L}$ vs. $63.21 \pm 15.04$ $\mu \mathrm{mol} / \mathrm{L}, \mathrm{CrCl} 70.57 \pm 23.67 \mathrm{ml} / \mathrm{min}$ vs. $68.94 \pm 21.85 \mathrm{ml} / \mathrm{min}$, and BUN $5.66 \pm 3.46$ vs. $5.44 \pm 3.18$ $\mathrm{mmol} / \mathrm{L}$, respectively).(Figure 1)

Figure 1.The mean $\mathrm{Cr}, \mathrm{CrCl}$ and $\mathrm{BUN}$ at baseline,6 months and 12 months during follow-up period.

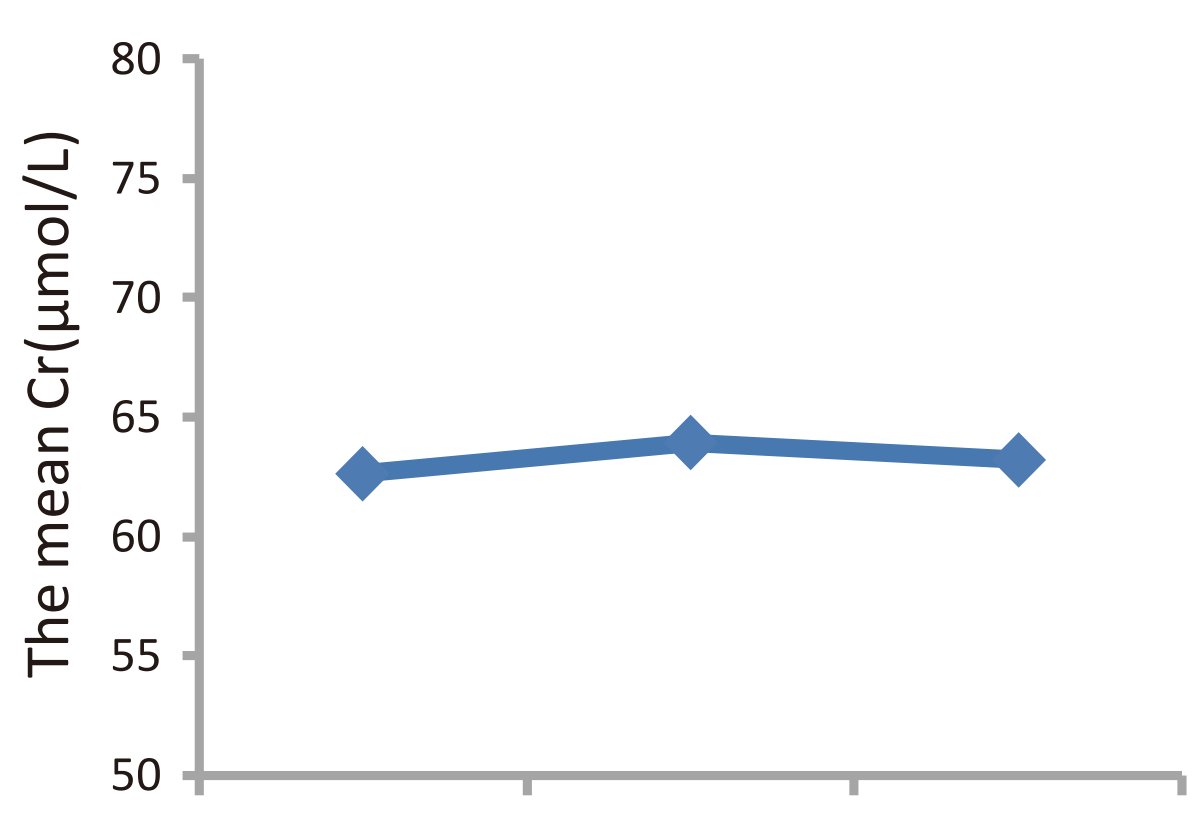

Baseline 6 months 12 months

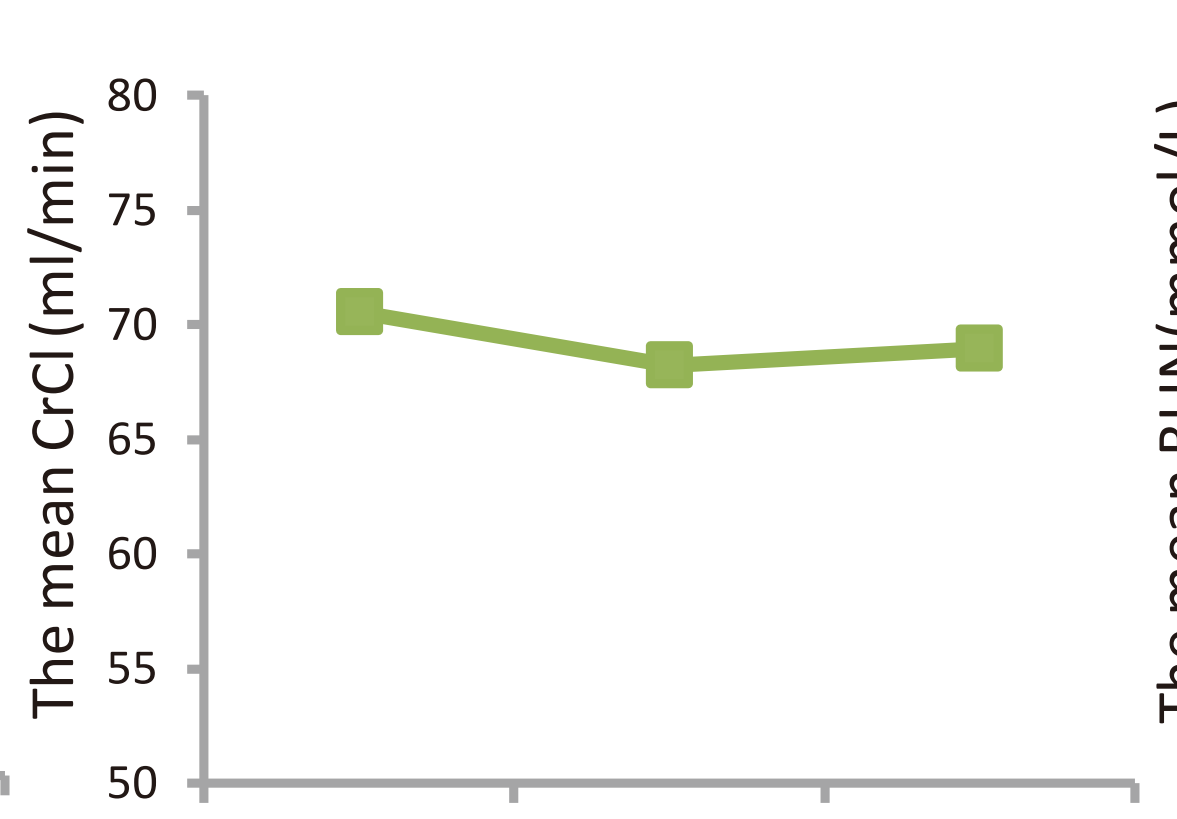

Baseline 6 month 12 month

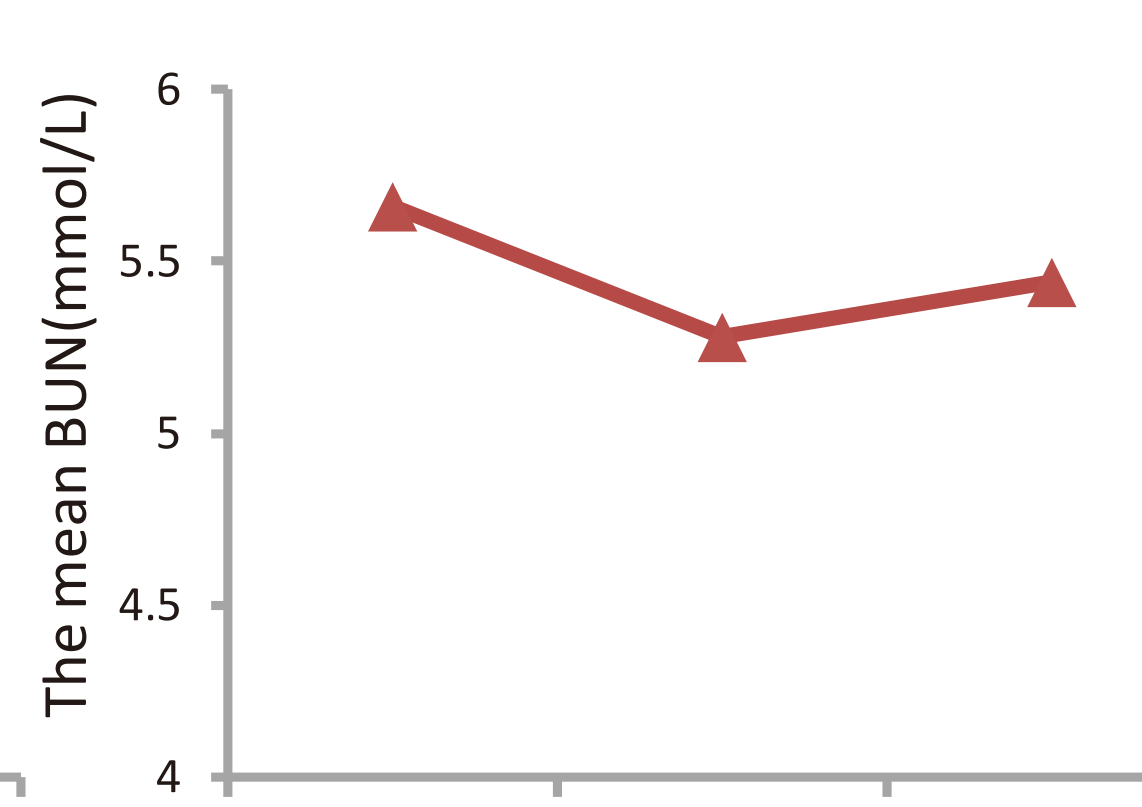

Baseline 6 months 12 months
- Creatinine increase of more than $0.5 \mathrm{mg} / \mathrm{dl}$ compared to baseline was found in only one patient $(0.38 \%)$ at 12 month.

- The patients' baseline average $\mathrm{CrCl}$ was $70.57 \pm 23.67 \mathrm{ml} / \mathrm{min}$. During one year follow-up, $\mathrm{CrCl}$ decline under $35 \mathrm{ml} / \mathrm{min}$ was found in 9 patients $(9 / 257,3.50 \%)$ with moderate renal impairment at baseline. (Table 1)

Table 1. Patients with $\mathrm{CrCl}<35 \mathrm{ml} / \mathrm{min}$ at follow-up

\begin{tabular}{|cccc|}
\hline Patient & $\begin{array}{c}\mathrm{CrCl} \text { baseline } \\
(\mathrm{ml} / \mathrm{min})\end{array}$ & $\begin{array}{c}\mathrm{CrCl} \text { at 6 months } \\
(\mathrm{ml} / \mathrm{min})\end{array}$ & $\begin{array}{c}\mathrm{CrCl} \text { at 12 months } \\
(\mathrm{ml} / \mathrm{min})\end{array}$ \\
\hline 1 & 39.08 & - & 33.83 \\
\hline 2 & 35.52 & 33.03 & 28.85 \\
\hline 3 & 37.48 & 31.58 & 35.23 \\
\hline 4 & 47.63 & 48.33 & 33.44 \\
\hline 5 & 38.80 & 33.21 & 32.51 \\
\hline 6 & 46.34 & 31.33 & 42.61 \\
\hline 7 & 38.39 & 34.20 & 35.12 \\
\hline 8 & 40.01 & 38.41 & 34.29 \\
\hline 9 & 36.61 & 39.20 & 34.76 \\
\hline
\end{tabular}

\section{RESULTS(Cont'd)}

\section{Adverse Events}

- A total of 42 patients (11.26\%) experienced adverse events (AEs). (Table 2)

- The most common AEs were fever (6.17\%) and musculoskeletal pain (1.61\%), while other AEs occurred below 1 percent.

- Serious adverse events were reported in 4 patients, including 3 deaths due to pneumonia, lung cancer and gastric perforation, which were not considered by the investigators to be drug related.

\section{Table 2.Adverse Events}

\begin{tabular}{|l|ccc|}
\hline AEs & No. of pts & $\begin{array}{c}\text { Frequency } \\
\text { of events }\end{array}$ & $\begin{array}{c}\text { Rate } \\
(\%)\end{array}$ \\
\hline Systemic events & 27 & 30 & 7.24 \\
\hline Pyrexia & 23 & 23 & 6.17 \\
\hline Pain & 3 & 3 & 0.80 \\
\hline Fatigue & 3 & 3 & 0.80 \\
\hline Influenzalike symptoms & 1 & 1 & 0.27 \\
\hline Musculoskeletal system events & 8 & 8 & 2.14 \\
\hline Myalgia & 6 & 6 & 1.61 \\
\hline Bone Pain & 2 & 2 & 0.54 \\
\hline Gastrointestinal system events & 6 & 9 & 1.61 \\
\hline Nausea & 3 & 3 & 0.80 \\
\hline Vomiting & 3 & 3 & 0.80 \\
\hline Diarrhea & 2 & 2 & 0.54 \\
\hline Gastrointestinal reactions & 1 & 1 & 0.27 \\
\hline The central and peripheral nervous system events & 5 & 6 & 1.34 \\
\hline Dizziness & 3 & 3 & 0.80 \\
\hline Drowsiness & 2 & 2 & 0.54 \\
\hline Headache & 1 & 1 & 0.27 \\
\hline Skin and its accessories events & 2 & 3 & 0.54 \\
\hline Pruritus & 2 & 3 & 0.54 \\
\hline Urinary system events & 1 & 1 & 0.27 \\
\hline Abnormal renal function & 1 & 1 & 0.27 \\
\hline
\end{tabular}

Adverse events were categorized according to codes used in the WHO Drug Adverse Reactions Database.

Tolerability

- After treatment for 12 month, the tolerability satisfactions evaluated by investigators were significant consistent with those by patients $(P<0.001)$. The proportion of "very good" tolerability evaluations in patients was $96.28 \%$, which was similar to that in investigators (96.43\%).

- $81.01 \%$ (290) of all enrolled patients were willing to continue the Zol treatment. And $91.79 \%$ of patients who completed the study continued Zol infusion in the next year.

\section{CONCLUSIONS}

- Once yearly zoledronic acid administration was associated with a good safety profile and generally well tolerated in Chinese PMO patients.

\section{REFERENCES}

- The main result of ZOOM study was accepted as posters on ASBMR Annual Meeting (Minneapolis, Minnesota, October 12-15,2012.Poster \# LB-SA 19) and IOF Regionals-3rd Asia-Pacific Osteoporosis Meeting (Kuala Lumpur, Malaysia,December 13-16,2012.Poster \# P321).

\section{ACKNOWLEDGMENT}

- This study was sponsored by Beijing Novartis Pharma Ltd. 